\title{
PREPARAÇÃO DE INIBIDORES DA AOX BASEADOS NA ESTRUTURA DOS PRODUTOS NATURAIS COLETOCLORINA B \& D
}

\section{Gabriel S. A. Zamboni, Paulo C. S. Costa, Silvana Rocco, Gonçalo Pereira e Paulo C. M. L. Miranda.}

\section{Resumo}

Buscou-se desenvolver uma rota sintética para a formação de inibidores da AOX baseados nas estruturas das coletoclorinas B e D. O método envolve a adição de Michael do acetoacetato de etila sobre o 3-tosilcrotonato de etila formando uma 2-pirona como intermediário e sua posterior isomerização e derivatização.

\section{Palavras-chave:}

Inibidores da oxidase alternativa (AOX), Resorcilatos, Coletoclorinas.

\section{Introdução}

A oxidase alternativa $(A O X)$ é uma enzima presente na membrana mitocondrial interna capaz de catalisar a oxidação do ubiquinol e a redução do oxigênio, fornecendo assim uma via alternativa à cadeia de transporte de elétrons, anterior à ação do complexo III. Desta forma, a AOX confere um mecanismo de produção de ATP resistente à ação de inibidores da via principal de respiração celular. ${ }^{1}$ Sendo assim, possui grande importância na virulência de fungos de interesse agroeconômico, como o Moniliphthora perniciosa, agente etiológico da Vassoura-de-Bruxa em cacaueiros ${ }^{2}$.

Tendo isso em vista, buscou-se sintetizar inibidores da AOX baseados em moléculas conhecidas por apresentarem atividade inibitória, como a as coletoclorinas $^{3}(\underline{1})$, com foco na estrutura da coletoclorina $B(\underline{\mathbf{1 a}})$ e $D(\underline{\mathbf{1 b}})$.<smiles>[2H]c1c(O)c(Cl)c(C)c(C=O)c1O</smiles>

\section{$\mathbf{R}=$}

a)<smiles>CC=C(C)CCC=C(C)C</smiles>

b)<smiles>CC=C(C)C</smiles>

Figura 1. Estruturas da a) coletoclorina $B$ e b) coletoclorina $D$.

\section{Resultados e Discussão}

A estratégia de formação dos resorcilatos partiu de uma adição de Michael entre o acetoacetato de etila e o 3tosilcrotonato de etila (2) , formando a 2-pirona ( $\underline{3})$, a qual foi isomerizada pelo uso de dois equivalentes de diisopropilamideto de lítio obtendo o 2,4-diidroxi-6metilbenzoato de etila (4).

Modificações da estrutura de $\underline{\mathbf{3}}$ foram estudadas, entre elas a halogenação da posição 3 do anel ( $\mathrm{Cl}$ e $\mathrm{Br})$. O grupo terpênico seria inserido na molécula de acetoacetato de etila, já que $\underline{\mathbf{3}}$ se apresentou inerte nas diversas condições testadas para a prenilação da metila da posição 6, através da reação do 1-bromo-3metilbuteno com a 2-pirona desprotonada. A carboxietila seria posteriormente reduzida ao respectivo aldeído.

Estuda-se substituir a carboxietila de $\underline{\mathbf{3}}$ por um grupo ciano, tendo como material de partida a cianoacetona ao invés do acetoacetato de etila. A 4,6-dimetil-2-oxo-2Hpiran-5-carbonitrila já foi preparada pelo grupo, tendo

como objetivo diminuir o impedimento estéreo do grupo presente na posição 5 , facilitando o ataque de um nucleófilo que realize a abertura do anel para a posterior isomerização, e manter a ressonância com a dupla ligação, aumentando a acidez do hidrogênio da metila da posição 6 facilitando a alquilação desse carbono.

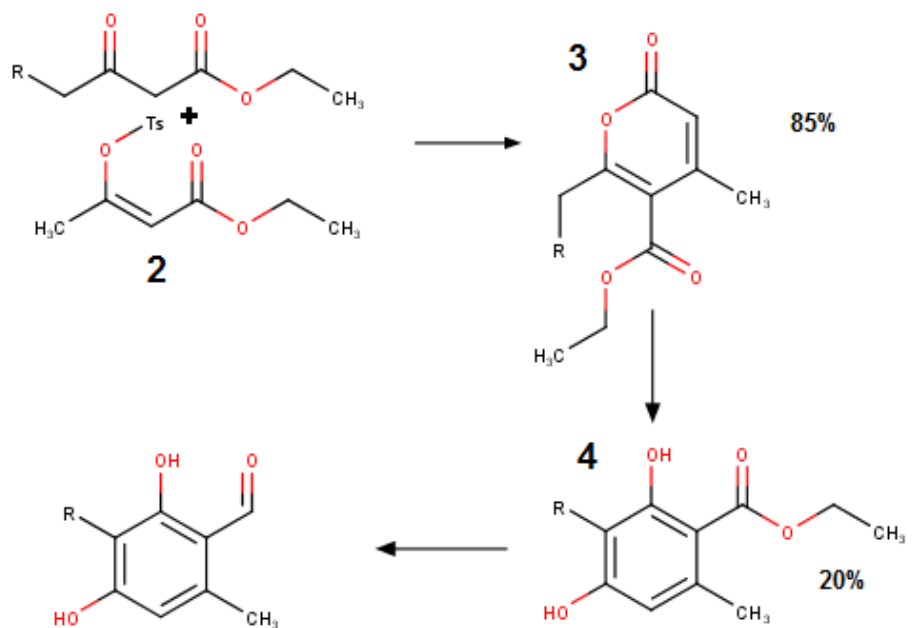

Figura 2. Rota sintética proposta para a preparação de compostos resorcilados precursores das coletoclorinas $B$

( $R=$ geranil) e $D(R=$ prenil). Os rendimentos são indicados para $\mathrm{R}=\mathrm{H}$. O rendimento da produção de 2 foi de $90 \%$.

\section{Conclusões}

Através dos estudos realizados foi possível o avanço na síntese das coletoclorinas $B$ e $D$, obtendo-se intermediários importantes da rota sintética proposta.

\section{Agradecimentos}

Ao CNPq, pela bolsa concedida. Ao Paulo Costa, pela ajuda e paciência. Ao Prof. Dr. Paulo Miranda, pela oportunidade.

\footnotetext{
1 McDonald A. E., Vanlerberghe G. C. Comp Biochem Physiol - Part D GenomicsProteomics, 2006, 1, 357.

2 Meinhardt, L. W.; Rincones, J.; Bailey, B. A.; Aime, M. C.; Griffith, G. W.; Zhang, D.; Pereira, G. A., Mol. Plant Pathol. 2008, 9, 577.

${ }^{3}$ Moore A. L., Shiba T., Young L., Harada S., Kita K., Ito K. Unravelin G. Annu. Rev.Plant Biol. 2013., 64, 637.
} 